\title{
Article/Artigo
}

\section{Evaluation of an enzyme immunoassay for clinical diagnosis of neurocysticercosis in symptomatic patients}

\author{
Avaliação de um teste imunoenzimático para o diagnóstico clínico de neurocisticercose em \\ pacientes sintomáticos
}

Reynaldo Mendes de Carvalho Junior ${ }^{1}$, Dorcas Lamounier Costa ${ }^{2}$, Savyo Carvalho Soares ${ }^{3}$ and Carlos Henrique Nery Costa $^{3,4}$

\begin{abstract}
Introduction: Neurocysticercosis is an infection of the human central nervous system caused by the metacestode larvae of Taenia solium. Neurocysticercosis is the most common parasitic disease in developing countries. Epilepsy is the most common clinical manifestation. Difficulties in confirming the diagnosis motivated the evaluation of the enzyme-linked immunosorbent assay on cerebral spinal fluid (CSF). Methods: Twenty-two patients with NCC and 44 control patients were studied. CSF was analyzed using a commercial ELISA kit developed for NCC. Sensitivity and specificity were measured and a multivariate logistic regression was performed. Results: Sensitivity and specificity of ELISA were $31.8 \%$ and $100 \%$, respectively, with accuracy of $77.3 \%$. Only the size of the lesions proved to be important for performance of the test. Conclusions: The results showed that ELISA contributes to the diagnosis of neurocysticercosis if the result is negative or if the patient has a lesion of $2 \mathrm{~cm}$ or more.
\end{abstract}

Keywords: ELISA. Neurocysticercosis. Cysticercus cellulosae. Taenia solium. Epilepsy.

\section{RESUMO}

Introdução: Neurocisticercose é a infecção do sistema nervoso central causada pela larva metacestódea da Taenia solium. Neurocisticercose é a parasitose mais comum nos países em desenvolvimento. Epilepsia é a sua manifestação clínica mais comum. A dificuldade para confirmar o diagnóstico motivou a avaliação do ensaio imunoenzimático ligado à enzima no líquido cérebro-espinhal. Métodos: Vinte e dois pacientes com NCC e 44 pacientes controles foram estudados. Líquido cérebro-espinhal foi analisado por um kit ELISA comercial desenvolvido para NCC. A sensibilidade e especificidade foram medidas e uma análise multivariada de regressão logística foi realizada. Resultados: A sensibilidade e a especificidade de ELISA foram, respectivamente, 31,8\% e 100\%, com acurácia de 77,3\%. Apenas o tamanho das lesões mostrou-se importante para o desempenho do teste. Conclusões: Este estudo concluiu que ELISA contribui para o diagnóstico de NCC, caso o teste seja negativo ou caso o paciente seja portador de lesão cuja dimensão seja igual ou maior que dois centímetros.

Palavras-chaves: ELISA. Neurocisticercose. Larva metacestódea. Taenia solium. Epilepsia.

1.Department of Specializing Medicine, Federal University of Piaui, Teresina, PI, Brazil. 2. Department of Mother and Child, Health Sciences Center, Federal University of Piaui, Teresina, PI, Brazil. 3. Institute of Tropical Diseases "Natan Portella”, Department of Health of the State of Piaui, Teresina, PI, Brazil. 4. Department of Community Medicine, Health Sciences Center, Federal University of Piaui, Teresina, PI, Brazil.

Address to: Dr. Reynaldo Mendes de Carvalho Júnior. R. Agnelo Pereira da Silva 3457, São João, 64045-260 Teresina, PI, Brazil.

Phone: 5586 3233-2628; Fax: 5586 3221-9148

e-mail: reynaldomendes@globo.com

Received in 20/02/2010

Accepted in 01/09/2010

\section{INTRODUCTION}

Neurocysticercosis is an infection of the central nervous system (CNS) by the metacestode larvae of Taenia solium. Involvement of the CNS is confirmed in $60 \%$ to $90 \%$ of patients with cysticercosis ${ }^{1}$, which is the most common parasitic disease in developing countries and constitutes a serious public health problem $^{2}$. In fact, it is estimated that approximately 20 million people are infected with T. solium cysticercosis and of these, 50.000 die of NCC each year ${ }^{3,4}$.

Taeniasis and cysticercosis are diseases caused by the same parasite at different biological stages: Taenia solium is the adult worm and metacestode larvae is the larval form. While taeniasis only develops in the small intestine, the embryo is able to invade various tissues throughout the blood system and in particularly the brain parenchyma. Implantation of the encapsulated embryo inside the skull causes clinical manifestations. These are related to factors, including: its location in the nervous tissue itself, within the ventricles or the subarachnoid cistern; and the size and number of lesions and their stage of development, which reflect its biological activity or inactivity. In addition to these factors that are intrinsic to the parasite and the number of infections suffered by the host, the strength of the host's immune defense is also important and sometimes leads to diagnostic difficulties ${ }^{2,5-8}$.

Imaging tests, such as computed tomography (CT) and nuclear magnetic resonance (MRI), have revolutionized the diagnosis of the disease. However, besides clinical polymorphism, several of the factors listed above form different image patterns with CT and MRI, which leads to difficulties in differential diagnosis. Imaging limitations reinforce the importance of clinical and epidemiological studies for the diagnosis of neurocysticercosis, resulting in the need to detect anti-cysticercosis antibodies as part of the diagnostic tools ${ }^{9,10}$.

Low cost and simplicity have made the enzymelinked immunosorbent assay (ELISA) the most widely used standard in research and clinical applications. 
This study evaluated the accuracy of a commercial ELISA assay performed on CSF for the diagnosis of neurocysticercosis, by assessing its sensitivity and specificity in patients with a confirmed diagnosis of neurocysticercosis and in patients with benign viral meningitis.

\section{METHODS}

A sample of patients with a definitive diagnosis of neurocysticercosis was studied and compared with a control group that consisted of patients without neurocysticercosis and with clinical picture and CSF exam compatible with benign viral meningitis.

After approval of the research project by the Ethics in Research Committee of the Federal University of Piauí and Getulio Vargas Hospital, the study began and data was collected from April 2008 to July 2009. This study respected and safely preserved all ethical aspects of the patients who agreed to collaborate with the study as well as all people directly and indirectly involved in the work. All patients or guardians signed an informed consent form. All individuals in the study lived in Teresina or in other cities in the States of Piauí and Maranhão. They sought medical care in Teresina and were referred to the researcher. The first group consisted of 22 patients diagnosed with neurocysticercosis, selected according to the diagnostic criteria proposed by Del Brutto 5 . A definitive diagnosis of neurocysticercosis was made by imaging in 16 patients and by pathological evidence in 6 others. The second group consisted of 44 patients with benign viral meningitis (group MVB) and without clinical manifestations and imaging compatible with neurocysticercosis. Antigen from the extract of cysticerci of Taenia solium removed from the carcasses of pigs was used and, after maceration, the antigenic proteins were separated using high power ultrasound resulting in products with the commercial name Enzitest ${ }^{\circledR}$ Cysticercosis IgG test for anti-metacestode larvae of Taenia solium (RNA Laboratories Ltda, Cascavel, Paraná). The immunoassay ELISA was applied to undiluted lumbar CSF only. The test was repeated in cases where the ELISA result was positive

\section{RESULTS}

\section{Sociodemographic profile of the sample studied}

The neurocysticercosis group consisted of 14 men and 8 women, aged from 12 to 58 years-old, with a mean of 28 years-old. All of these patients presented live cysts. One patient came from a rural area in the State of Maranhão, while 21 lived in the State of Piauí: six on the outskirts and two in urban areas (UA) of Teresina, the capital of Piauí; 10 from a rural area; and three from other cities in the interior of Piauí. Additional tests included: 12 patients had a CT; four had an MRI; and six had a CT and an MRI. According to several studies, the vital stages of metacestode larvae of Taenia solium in the cranial cavity were estimated according to the appearance on imaging exams $\mathrm{s}^{6,11,12}$. Although all patients in the neurocysticercosis group presented active lesions, the pattern of larval imaging was heterogeneous in 13 (59.1\%) patients, 8 of which displayed vesicular and calcified forms; two showed colloidal and granular phases; one presented both vesicular and granular aspects; one presented vesicular and colloidal forms; and one presented vesicular, granular and calcified forms. Of the other 9 (40.9\%) patients with neurocysticercosis, 7 showed the vesicular larval phase, one displayed colloidal and one presented the granular form. The predominant location of the larvae was the brain parenchyma in $16(72.8 \%)$ patients, the cerebral ventricles in three $(13.6 \%)$ and in more than one compartment in three (13.6\%) patients. Regarding the dimensions of the lesion, out of 75 active lesions in 22 patients, six measured $3 \mathrm{~cm}$ or more, most were $6 \mathrm{~cm}$ at the greatest diameter. Three occupied the brain parenchyma and three occupied the ventricular cavity and of these six, only one was not removed surgically.

In the control group, all patients showed signs of meningeal irritation, with headache and neck stiffness. The sample included 29 men and 15 women, from 2 to 45 years of age, with a mean of 16 years-old. Forty-two patients presented a normal CT exam, but for two, CT scan showed mild prominence of the lateral ventricles, which was interpreted as anatomical variation. Of the 44 subjects, 21 lived in Teresina, Piauí, 14 were from neighboring cities in Piauí and 9 from neighboring towns in Maranhão. The sample consisted of 30 students, six farmers, four children under four years of age and individuals from four other professions. Thirty-two patients had finished elementary school, five had finished high school, one had finished college and two claimed to be illiterate.

Table 1 shows the sensitivity and specificity of ELISA, which were $31.8 \%$, with a $95 \%$ confidence interval (CI) of 14.7-54.90 and $100 \%$ (95\%CI 90.0-100.0), respectively, while the positive and negative predictive values were $100 \%$ (95\%CI 56.1-100.0) and $74.6 \%$ (95\%CI 61.3-84.6), respectively. The accuracy of the test was $77.3 \%$.

Seven patients, between 15 and 49 years-old, tested positive for ELISA. Five of these patients had epilepsy, which was associated

TABLE 1 - Performance of a commercial enzyme-linked immunoassay (Enzitest $\mathbb{R}$ Cysticercosis IgG) on the cerebrospinal fluid of patients with neurocysticercosis and of patients with benign viral meningitis.

\begin{tabular}{lrrrrrr}
\hline & \multicolumn{4}{c}{ Neurocysticercosis } \\
\cline { 2 - 3 } Elisa in CSF & \multicolumn{2}{c}{ present } & & \multicolumn{2}{c}{ absent } \\
\cline { 2 - 5 } \cline { 5 - 7 } Neactive & $\mathrm{n}$ & $\%$ & & $\mathrm{n}$ & $\%$ \\
\hline Nonreactive & 7 & 31.8 & & 0 & 0.0 \\
\hline Total of patients & 15 & 68.2 & & 44 & 100.0 \\
\hline
\end{tabular}

with hydrocephalus in two. However, hydrocephalus was present in three of the seven patients. The neurological examination was normal in two $(28.6 \%)$ patients, while four showed signs of intracranial hypertension and two presented cerebellar ataxia. Of the 15 patients whose CSF was negative, 12 (80\%) had epilepsy as a main manifestation and normal neurological examination, while three presented hydrocephalus and intracranial hypertension syndrome.

Of the seven patients with reactive ELISA, five presented two or more cysts, but all with cysts in the vesicular stage. Only one patient had a cyst in the vesicular and colloidal phase. Of the seven, only one presented an inactive lesion, with 108 calcified nodules in a CT of the cranium. Cysts in the vesicular phase were detected in 11 of the 15 patients with nonreactive ELISA. Of these, only one patient had more than 5 vesicles, four presented from 2 to 5 , while six patients presented only one vesicle. Furthermore, 10 patients presented calcified nodules, four presented cysts in the granular phase and only one patient showed a cyst in the colloidal phase.

Six of the seven patients with reactive ELISA presented cysts greater than or equal to $2 \mathrm{~cm}$. Four patients presented cysts in the brain parenchyma and two presented cysts only in the ventricular cavities. Only one presented cysts in the three intracranial compartments. In the subgroup with a reactive ELISA, the mean number of lesions was six. The ratio of the number and size of lesions with the performance of ELISA is shown in Table 2. 
TABLE 2 - Size and number of intracranial lesions of patients with neurocysticercosis according

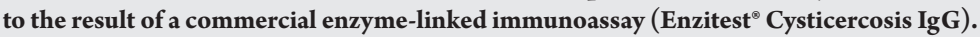

\begin{tabular}{|c|c|c|c|c|c|c|}
\hline \multirow[b]{3}{*}{ Size of the largest lesion $(\mathrm{cm})$} & \multicolumn{6}{|c|}{ ELISA result } \\
\hline & \multicolumn{3}{|r|}{ reactive } & \multicolumn{3}{|c|}{ nonreactive } \\
\hline & $\mathrm{n}$ & $\%$ & $\begin{array}{l}\text { total number of } \\
\text { lesions per patient } \\
\text { (any size) }\end{array}$ & $\mathrm{n}$ & $\%$ & $\begin{array}{l}\text { total number of } \\
\text { lesions per patient } \\
\text { (any size) }\end{array}$ \\
\hline$\leq 1$ & 1 & 14.3 & 1 & 14 & 93.3 & 1 to 18 \\
\hline 2 & 1 & 14.3 & 2 & 0 & 0.0 & 0 \\
\hline 3 & 4 & 57.1 & 1 to 113 & 1 & 6.7 & 1 \\
\hline$>3$ & 1 & 14.3 & 16 & 0 & 0.0 & 0 \\
\hline Total & 7 & 100.0 & - & 15 & 100.0 & - \\
\hline
\end{tabular}

In univariate analysis, the ELISA test was associated with the presence of vesicles $(p=0.03)$, epilepsy $(p<0.001)$ and size of lesions identified in CT and MRI $(\mathrm{p}<0.001)$. In multivariate analysis with logistic regression, only the size of the lesions proved to be important for the performance of the test. Analysis revealed that the reactivity of the test was positively correlated with larger lesions. Finally, the performance of the ELISA test was assessed by analysis of receiver operating characteristic (ROC) curve, which showed that the sensitivity and specificity of the ELISA were higher when the lesions measured between 2 and $3 \mathrm{~cm}$. The area under the curve for this model was 0.92 (Figure 1).

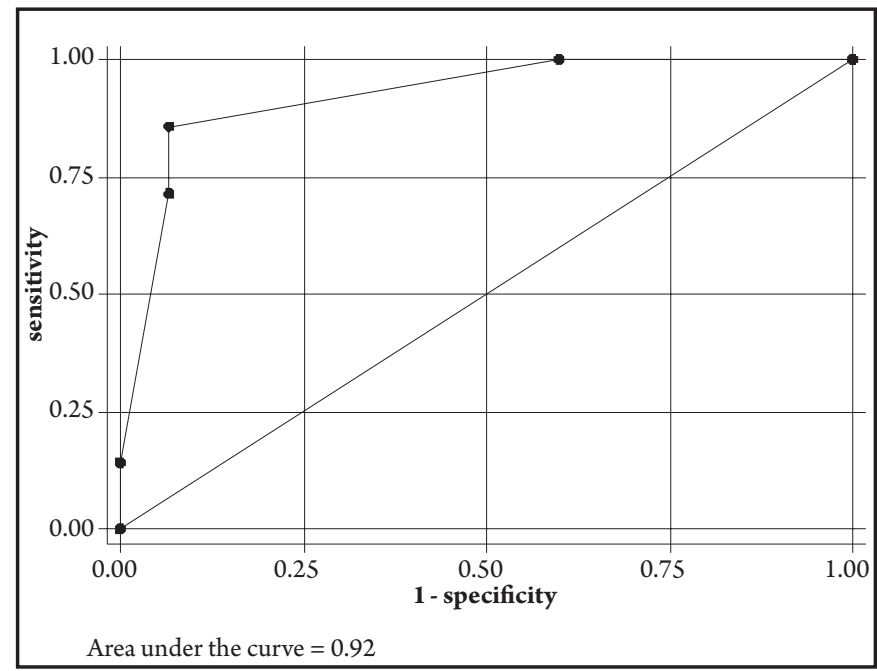

FIGURE 1 - Graph of the area under ROC curve showing the prediction model of a commercial enzyme-linked immunoassay (Enzitest ${ }^{\circledR}$ cysticercosis IgG) in patients with neurocysticercosis through the variable according to the size of the lesion.

\section{DISCUSSION}

In this study, there was a predominance of males in the group of patients with neurocysticercosis, which is consistent with the literature ${ }^{13}$. This fact is certainly associated with profession and schooling, because in rural areas, field work is usually carried out by people with little or no education. Therefore, most of these people have a poor social and economic backgrounds. On the other hand, with the exception of two women, most worked at home or were students and none were illiterate or field workers. Having more opportunity to study and less contact with crops, women are less exposed to neurocysticercosis. Likewise, the results also showed that half of the patients in the neurocysticercosis group lived in rural areas. However, the outskirts of Brazil's poorest large cities lack basic sanitation and most residents in the outskirts of Teresina have a low educational level and perform daily tasks similar to those of individuals who live in rural areas, as seen in other areas where neurocysticercosis transmission occurs ${ }^{14,15}$. Observation of the life cycle of the parasite reveals that the existence of infected pigs in an urban setting may be the essential link to maintaining the endemicity of the disease, because pigs are carriers of T. solium, which spreads neurocysticercosis in the domestic environment and its surroundings $s^{4}$. Thus, only when the urban area is inhabited by people with a reasonable educational level, with a clean drinking water supply and proper conditions of sanitation, will the conditions for the prevention and eradication of neurocysticercosis become available.

In this study the predominant location of cysts was the brain parenchyma, which is in agreement with the literature ${ }^{16}$. In the nonreactive ELISA subgroup, the lesions were more restricted to the parenchyma, while the positive subgroup showed the greatest diversity of lesion sites, especially ventricular lesions. Nevertheless, no statistical correlation occurred between lesion location and the sensitivity or specificity of the serological tests. The clinical presentations were varied, but followed the pattern described in the literature ${ }^{13,17}$. Epilepsy was the predominant clinical entity, affecting $77.3 \%$ of patients with neurocysticercosis and was clearly associated with the presence of lesions in the brain parenchyma, the most frequent site of cysticercotic lesions. Although present in both groups of patients with positive and negative ELISA, positive correlation occurred between epilepsy and performance of the ELISA test in the univariate analysis $(\mathrm{p}<0.001)$. However, the multivariate analysis confirmed the independence of all these associations.

All patients with neurocysticercosis presented active lesions and most of those with negative ELISA also had calcified lesions. Several studies have shown that the performance of the ELISA method for diagnosis of neurocysticercosis is better in the stages of cysticercus degeneration ${ }^{18-20}$. These results are different from the present study, where six of the 15 patients with negative ELISA presented cysts in degeneration, while only one of the seven patients with positive ELISA presented cysts in degeneration. Therefore, detectable antibodies by ELISA were present only with vesicular lesions and not with cysts that were in degeneration and inactive. Individuals with a greater number and size of lesions tested positive for ELISA of the CSF. One study showed that the presence of a single parenchymal lesion is related to low sensitivity, even with the Western blot method, which is the gold standard for serological diagnosis of neurocysticercosis ${ }^{19}$, suggesting some immune tolerance to the parasite and the absence of antibody production when only one cysts is present ${ }^{17,18}$.

Multivariate analysis in the present study showed that the only factor associated with the accuracy of the ELISA method was the size of the cyst, particularly in lesions 2 to $3 \mathrm{~cm}$ in diameter, since out of the seven positive ELISA patients, five presented cysts equal to or greater than $3 \mathrm{~cm}$ and among these, three underwent neurosurgery, an event indicative of greater severity. The data support the idea that cysticerci that are diagnosed when they are larger are usually in the vesicular stage and thus have escaped the degeneration process, as a result of 
a particular host immune response. Therefore the data support the hypothesis that the larger the cyst, the older they are and that older cysts maintain a longer immune response leading to the production of antibodies, which explains why larger cysts induce the production of more antibodies, as detected by ELISA from the CSF.

A multifaceted presentation of cysticercosis in the CNS implies that multiple variables are related to both the host and the parasite, leading to a series of combinations with each other, which should be taken into account when looking for statistical correlation between the performance of ELISA and each of these variables. Likewise, the discrepancy shows that the variables are mutually independent; i.e., the effects related to one do not add up to those relating to the other. The variable related to the number and structure of antibodies in the evolution of the disease should also be considered as very unstable, by considering the proposal of Schant ${ }^{16}$, that bodies infected with cysticerci produce antibodies with different structure according to the biological phase of the cyst.

Reviewing the literature, it appears that the ELISA method has shown different sensitivity and specificity scores ${ }^{17-28}$. This study determined a sensitivity of $31.8 \%$ and specificity of $100 \%$ for the ELISA method in CSF in relation to diagnosing neurocysticercosis, which implies low sensitivity of ELISA for diagnosing neurocysticercosis, with a $68.3 \%$ rate of false negative. However, the results indicate a positive predictive value of $100 \%$, emphasizing the efficiency of the test at ensuring that a positive result provides the professional with the certainty to treat the individual as a patient with neurocysticercosis.

From the above data, it can be concluded that a positive ELISA test is useful for the diagnosis of neurocysticercosis. However, a negative test result does not indicate absence of neurocysticercosis. ELISA is indicated to confirm the diagnosis of symptomatic patients whose imaging reveals lesions that are two centimeters or more. For patients with lesions that are smaller than two centimeters and whose lesions are in the vesicular stage, other diagnostic tools should be used.

\section{ACKNOWLEDGMENTS}

Nurse Fabrícia Castelo Branco de Andrade, together with Célia Regina Martins Ferreira and Fernando Oliveira Silva, were indispensable for patient identification and collecting and storing samples. The authors would like to thank the Fundação Municipal de Saúde de Teresina and Instituto de Doenças Tropicais Nathan Portella for the critical support to develop this study.

\section{CONFLICT OF INTEREST}

The authors declare that there is no conflict of interest.

\section{FINANCIAL SUPPORT}

The authors would like to thank the Fundação Municipal de Saúde de Teresina for the financial support of this study.

\section{REFERENCES}

1. Hawk MW, Shahlaie K, Kee DK, Theis JH. Surgical Neurocysticercosis: a review. Neurology 2005; 63:123-132.

2. Di Pentima MC, White AC. Neurocysticercosis: Controversies in Management Seminars in Pediatric. Infec Dis 2000; 11:261-268.

3. Ito A, Takayanagui OM, Sako Y, Sato MO, Odashima NS, Yamasaki H, et al. Neurocysticercosis: clinical manifestations, neuroimaging, serology and molecular confirmation of histopathologic specimens. Southeast Asian J Trop Med Public Health 2006; 37:74-81.

4. Mafojane NA, Appleton CC, Krecek RC, Michael LM, Willingham-III AL. The current status of neurocysticercosis in Eastern and Southern Africa. Acta Tropica 2003; 87:25-33.

5. Del Brutto OH, Noshir HW, Dumas M, Cruz M, Tsang VCW, Schantz PM. Proposal of diagnostic criteria for human cysticercosis and neurocysticercosis. J Neuro Sci 1996; 142:1-6.

6. Schantz PM. Progress in diagnosis, treatment and elimination of echinococcosis and cysticercosis. Parasitol Int 2006; 55:7-13.

7. Takayanagui OM, Leite JP. Neurocysticercosis. Rev Soc Bras Med Trop $2001 ; 34: 283-290$.

8. Villanueva M, Alcocer JL, Martínez J, Horna A. Cisticercosis intramedular. Arch Neurocien 2004; 9:110-113.

9. $\mathrm{Ng} \mathrm{SH}$, Tan TY, Fock KM. The value of MRI in the Diagnosis and Management of Neurocysticercosis. Singapore Med J 2000; 41:132-134.

10. Dorny P, Brandt J, Zoli A, Geerts S. Review article Immunodiagnostic tools for human and porcine cysticercosis. Acta Tropica 2003; 87:79-86.

11. Andrade-Filho AS, Figuerôa LFS, Andrade-Souza VM. Clinical Tomographic Correlations of 220 Patients with Neurocisticercosis, Bahia, Brazil. Braz J Infect Dis 2007; 11:114-117.

12. Sotelo J, Guerrero V, Rubio F. Neurocysticercosis: A New Classification Based on Active and Inactive Forms. Arch Inte Med 1985; 145:442-445.

13. Agapejev S. Aspectos Clínico-Epidemiológicos da Neurocisticercose no Brasil - Análise Crítica. Arq Neuropsiquiatr 2003; 61:822-828.

14. Lino-Junior RS, Faleiros ACG, Vinaud MC, Oliveira FA, Guimarães JV, Reis MA, et al. Anatomopathological aspects of neurocysticercosis in autopsied patients. Arq Neuropsiquiatr 2007; 65:87-89.

15. Freitas FIS, Meza-Lucas A, Lima CB, Costa W, Melo A. Estudo da cisticercose em pacientes portadores de epilepsia residentes em municípios do Cariri Paraibano. Arq Neuropsiquiatr 2005; 63:656-660.

16. Agarawal A, Khanal GP. Neurocysticercosis: a review. Nepal Journal of Neuroscience 2007; 3:80-84.

17. Barros JA, Barros HA, Barros JA. Diagnosis and treatment of neurocysticercosis. Rev Med 2003; 13: 240-243.

18. Barcelos ISC, Ferreira MS, Moura LP, Biondi GF, Costa-CruzJM. Use of the paired samples (cerebrospinal fluid and serum) inimmunodiagnostic of active and inactive human neurocysticercosis. Mem Inst Oswaldo Cruz 2005; 100:427-429.

19. Takayanagui OM, Odashima NS. Clinical aspects of neurocysticercosis Parasitol Int 2006; 55:111-115.

20. Casanova CS, Ribeiro MJSP, Gonçalves RR, Faria LC, Peralta JM, PuccioniSohler M. Influence of the cerebrospinal fluid laboratory parameters in the elisa test for neurocysticercosis using a total cysticerci antigen. Arq Neuropsiquiatr 2006; 64:55-59.

21. Flisser A. Taeniasis and cysticercosis due to Taenia solium. Prog Clin Parasitol 1994; 4:77-116.

22. Zini D, Farrell VJR, Wadee AA. The relationship of antibody levels to the clinical spectrum of human neurocysticercosis. J Neurol Neurosurg Psychiatry 1990; 53:656-651.

23. Pialarissi CS, Vaz AJ, Souza AMC, Nakamura PM, Camargo ED, Silva MV, et al. Estudo comparativo de testes sorológicos no diagnóstico imunológico da neurocisticercose. Rev Inst Med Trop 1987; 29:367-373.

24. Ramos-Kuri M, Montoya RM, Padilla A, Tzipe TG, Diaz ML, Sciutto E, et al. Immunodiagnosis of Neurocysticercosis - Disappointing Performance of Serology (Enzime-Linked Immunosorbent Assay) in an Unbiased Sample of Neurological Patients. Arch Neurol 1992; 49:633-636.

25. Macedo HW, Peralta RHS, Cipriano A, Sarmento MR, Vaz AJ, Peralta JM. Avaliação de testes imunológicos para o diagnóstico da neurocisticercose. J Bras Patol Med Lab 2002; 38:93-103.

26. Abraham R, Livramento JA, Leite CD, Pardini AX, Vaz AJ, Machado LD. Neurocysticercosis Relationship between Taenia antigen levels in CFS and MRI. Arq Neuropsiquiatr 2010; 68:7-11.

27. Suzuki LA, Arruda GC, Quagliato EMAB, Rossi CL. Evaluation of Taenia solium and Taenia crassiceps cysticercal antigens for immunodiagnosis of neurocysticercosis using ELISA on cerebrospinal fluid samples. Rev Soc Bras Med Trop 2007; 40:152-155.

28. Sahu PS, Parija SC, Narayan SK, Kumar D. Evaluation of an IgG-ELISA strategy using Taenia solium metacestode somatic and excretory-secretory antigens for diagnosis of neurocysticercosis revealing biological stage of the larvae. Acta Trop 2009; 110:38-45 